\title{
NIH streamlines research grants process
}

[WASHINGTON] The leaders of the National Institutes of Health (NIH) have approved a streamlined procedure for research grant applications that will require budgets to be based merely on multiples of $\$ 25,000$, not drawn up to the last cent.

The 'modular' grant format was recently given a provisional go-ahead by Harold Varmus, the NIH director, and other institute directors. The final details are expected to be approved by the directors within the next few weeks, with the scheme coming into effect with the round of grants for which applications are due on 1 February 1999.

Diana Jaeger, acting director of NIH's Office of Policy for Extramural Research Administration, says the aim of the streamlined process is to keep the focus of attention "primarily on the science", for applicants and reviewers alike. She says the NIH wants to "disengage" from intense budgetary negotiations that "add very little value to the grants process".

The new format has already been tested by several NIH institutes, and will apply to all investigator-initiated applications requesting less than $\$ 250,000$ in annual funding.
Under the scheme, applicants will be asked to provide a total figure for the cost of the project, expressed as a multiple of $\$ 25,000$, and a written justification.

The latter includes estimated figures for four categories of expenses: staff, major equipment, laboratory alterations and renovations, and contracts or arrangements as a member of a consortium. Other items, such as travel, supplies and expenses, will no longer have to be itemized.

The National Heart, Lung and Blood Institute (NHLBI) began piloting modular grants in 1995. Ron Geller, the director of its division of extramural affairs, says the process has meant that "the reviewers don't spend a lot of time worrying about whether travel should be cut from $\$ 1,200$ to $\$ 800$ ".

He says many investigators "felt overwhelmingly that it saved time, because they didn't have to deal with the detailed dollars in every single category". Geller says his reviewers found the $\$ 50,000$ increments used in an initial experiment too blunt.

Will the $\$ 25,000$ increments tempt applicants to round their costs upwards? "We'll be looking for that," says Jaeger, adding that the
NIH is ready to cut $\$ 25,000$ off any application that seems inflated. "Peer reviewers are also investigators, and they know what it costs to conduct a project." A first-year assessment conducted by the NIH will also watch for trends in average grant costs under the new scheme, she says.

One scientist who won a modular grant under a pilot project welcomes the procedure. Louis Ptacek says he is "very positive" about the process. Ptacek, a geneticist and Howard Hughes Medical Institute investigator at the University of Utah in Salt Lake City, last year won $\$ 200,000$ a year for four years from NHLBI and two other institutes to study advanced sleep phase syndrome, a rare sleep disorder.

Ptacek says that it was a "tremendous relief" not to have to contend with the budget detail of a traditional R01 application. "I had to give some general guidelines about how I intended to spend the money, but it didn't ask for the excruciating detail that is expected in an R01." He estimates that the modular grant format could eventually halve the time he spends drawing up figures for his grant applications.

MeredithWadman

\section{Bill tightens law against genetic discrimination by health insurers}

[WASHINGTON] Republican members of the US Senate are trying to fill the gaps in a 1996 law prohibiting genetic discrimination in health insurance coverage. A bill introduced last week would prohibit health insurers from using genetic information to deny individual insurance policies to people who have not been previously or recently insured.

This group was not protected under the Health Insurance Portability and Accountability Act of 1996, authored by Senator Edward Kennedy (Democrat, Massachusetts) and former Senator Nancy Kassebaum (Republican, Kansas).

Importantly, the new bill, the Patients' Bill of Rights Act, also prohibits health insurers - whether for groups or individuals from using genetic information to set premium costs. It bars insurers from requiring applicants or those already enrolled to take genetic tests or to divulge test results.

The bill, whose supporters are led by Don Nickles (Republican, Oklahoma), gives a broad definition of genetic information that includes not only an individual's genetic tests but also tests taken by that person's family members, as well as family histories of diseases that put the individual at a significantly increased risk of a disease.

The broad definition was applauded by the National Human Genome Research

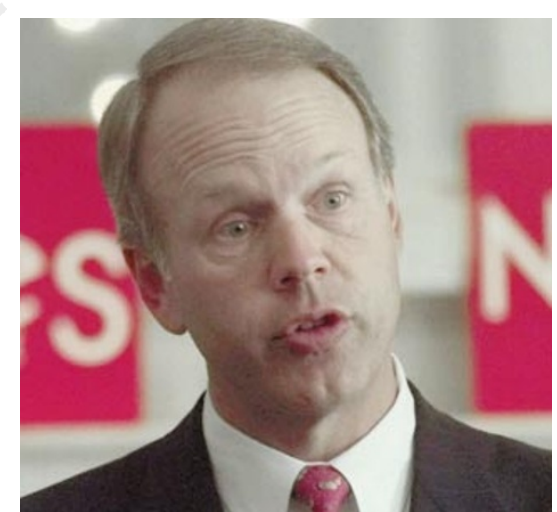

Nickles: bill would forbid health insurers from using genetic information to set premium costs.

Institute. "We are delighted that family history has been included here," says Kathy Hudson, the institute's assistant director for policy coordination.

But the breadth and reach of the bill's language on genetic discrimination has not gone down well with the Health Insurance Association of America, which says that its members do not currently use genetic information to deny coverage.

Dean Rosen, the association's senior vice-president of policy, says the bill would set a "really terrible" precedent as it would give the federal government authority over the setting of health insurers' rates, an area historically controlled by the states. He also argues that it would damage the market for individual insurance coverage, which is taken out by about 10 million Americans.

By guaranteeing individual policies to people who have long held back from buying health insurance but then receive genetic test results revealing them to be at increased risk of disease, "it forces people who have... held on to their insurance for years to subsidize the higher health costs of someone who has waited," says Rosen.

The effect of such behaviour in raising premium costs is not of the same concern to insurers in the group market because of its much larger size.

The genetic discrimination provisions are included in a broad bill that aims to protect the rights of patients in an era of managed healthcare. But the bill's other provisions apply only to the $\mathbf{4 8}$ million Americans in federally regulated health plans. In contrast, the genetic discrimination language encompasses an additional 100 million Americans in stateregulated plans, as well as individuals not currently insured.

Neither a competing Democratic bill, authored by Senator Tom Daschle (South Dakota) and Congressman John Dingell (Michigan), nor a bill from House Republican leaders, addresses genetic discrimination. It is not clear which of the three bills will prevail. 